\title{
Immune Inflammation Related to Obesity in Pregnant Women
}

\author{
DRAGOS VALENTIN CRAUCIUC ${ }^{1}$, ALLIA SINDILAR ${ }^{1 *}$, MADALINA DIAC ${ }^{1 *}$, DANIEL TABIAN ${ }^{1 *}$, SOFIA MIHAELA DAVID ${ }^{1}$, \\ DIANA BULGARU-ILIESCU1,2, EDUARD GRABRIEL CRAUCIUC 1,3 \\ ${ }^{1}$ Grigore T.Popa University of Medicine and Pharmacy,16 Universitatii Str., 700115, lasi, România \\ ${ }^{2}$ Institute of Legal Medicine of Iasi, 4 Buna Vestire Str., 700455, Iasi, Romania \\ 3Elena Doamna Clinical Hospital Iasi, 49 Elena Doamna Str., 700398, Iasi, Romania
}

\begin{abstract}
Although there are many conditions to be met for the disease to occur (genetic predisposition, environmental factors, stress, exposure to pollutants, noxes, xenobiotics, diet), chronic inflammation is the way how the body responds to these substances. Excess weight leads to an alteration of the immune response, to an increased oxidative stress, and damage to the cellular Deoxyribonucleic acid (DNA) structure. The study aims to evaluate inflammation in obese mothers. The study group consisted of 30 pregnant women in which inflammation was analysed, with a mean age of $30.80 \pm 6,94$ years old divided in 2 groups depending on their weight, that is 25 pregnant women with obesity and 5 normoponderal pregnant women. From the markers found in the blood samples, only CRP (AUC=0.740; IC95\%: 0.466-1.014), leptin $(A U C=0.616$; IC95\%: 0.296-0.936) and glycaemia ( $A U C=0.648$; IC95\%: 0.369-0.927) were good indicators of immune inflammation. The estimated risk of immune inflammation is 5 times higher in obese pregnancies with CRP levels above 6.
\end{abstract}

Keywords: obesity, immune inflammation, pregnant woman.

Excessive fat accumulation in the abdomen is associated with increased cardio-metabolic risk, regardless of age. The mechanisms underlying this process are numerous and have as an essential cause that perivisceral adiposity is metabolically active. Primary and secondary prophylaxis of central obesity through lifestyle changes have a very important role in avoiding non-communicable diseases and its assessment by simple somatic measurements should be part of a prophylactic medical examination [1].

Numerous studies have focused on the causal link between the presence of visceral adiposity and the increase in insulin resistance. However, there is no consensus on how this happens. One possibility may be that visceral adiposity is diabetogenic per se, secreting adipokines that decrease the insulin sensitivity of different tissues, but especially of the liver and muscles, the action being increased as the adipose tissue accumulates. Another possibility is that visceral fat would be an indicator of fat ectopic accumulation and lipotoxicity that occurs in parallel in the liver and muscle, resulting in insulin resistance in these tissues. A third possibility would be that excess lipid accumulation in visceral adipose tissue determines its acquisition of diabetogenic properties. It is proven that visceral fat accumulates macrophages that secrete proinflammatory cytokines that decrease insulin sensitivity. A fourth possibility would be that peripheral tissue lipotoxicity and cytokine secretion of perivisceral fat contribute together to systemic resistance to insulin [2].

The development of obesity is associated with substantial modulation of adipose tissue structure, involving adipogenesis, angiogenesis and remodelling of the extracellular matrix. These processes require proteolytic activity, mainly provided by fibrinolytic (plasminogen / plasmin) systems, matrix metalloproteinase and ADAM (a-disintergin and metalloproteinase) / ADAMTS (adisintergin and metalloproteinase with thrombospondin motifs). In early development of the adipose tissue, adipogenesis is closely associated with angiogenesis.
Thus, the adipose tissue triggers the formation of blood vessels and, in turn, endothelial cells of adipose tissue promote the differentiation of pre-adipocytes. Modulation of angiogenesis and proteolytic systems may have the potential to affect the development of adipose tissue [3]. Associated medical issues developed by the mother are likely to have impact later on the baby too [4-6].

Obesity in pregnancy increases the risk of certain complications such as [7-13]:

Gestational diabetes. Obese women are at increased risk of having diabetes than women with normal weight.

- Preeclampsia. Obesity increases the risk of developing high blood pressure and excess protein in the urine after the 20th week of pregnancy.

- Infections. The risk of urinary tract infections is increased. In addition, obesity increases the risk of postpartum infections, whether the baby is born vaginally or by caesarean.

- Thrombosis. Women who are obese during pregnancy have an increased risk of developing thrombi (blood clots) in the deep veins of the low er limbs, a serious condition that may be complicated by pulmonary thromboembolism.

- Obstructive sleep apnoea syndrome. It is a condition in which, during sleep, breathing stops for long periods of time.

- Prolonged pregnancy. Obesity increases the risk that pregnancy may extend beyond the 42-week term.

- Problems during labour. In obese pregnant women the induction of labour is much more common. Obesity may interfere with the use of certain pain control methods such as epidural anaesthesia.

- Caesarean section. Obesity increases the risk of elective caesarean surgery or in an emergency. Also, complications of caesarean surgery are more common, such as delayed wound healing or infections at incision level.

- Loss of pregnancy. Obesity has an increased risk of abortion or the birth of a dead child. 


\section{Purpose and objectives}

Obesity in pregnancy causes serious health problems for the child:

- Macrosomia. Obese women have a significant risk of having children that are larger than the average (macrosomes) and have a higher body fat than normal. Research has also shown an increased risk of obesity in childhood.

- Chronic conditions. Obesity in pregnancy increases the risk of the baby suffering from heart disease or diabetes as an adult.

- Congenital defects. There is a slightly increased risk of congenital heart disease or neural tube defects.

One of the main objectives of the study was to identify correlation between leptin levels during pregnancy in obese women with inflammatory markers. Changing the lifestyle can contribute to a healthier metabolic profile in obese pregnant women, which will reduce the risk of serious health problems in the product of conception.

\section{Experimental part}

Material and method

The study was a prospective, case control one, performed on a group of 30 pregnant women who gave birth to babies in the Obstetrics and Gynaecology Clinic belonging to Elena Doamna Hospital Iasi and were assessed the degree of immune inflammation associated to obesity.

The group studied consisted of 30 pregnant women, obese $(n=25)$, overweight and normal weighted $(n=5)$, who were harvested blood samples to determine the level of markers associated with the inflammatory process: $C$ reactive protein (CRP), leptin, insulin, glucose, Homeostatic Model Assessment for Insulin Resistance (HOMA).

C-reactive protein is a plasmatic protein of the pentraxin family and an acute phase reactant, very useful as a general inflammation marker. CRP levels above the cut point generally used to indicate an obvious source of infection or inflammation $>6 \mathrm{mg} / \mathrm{dL}$.

Patients were sampled by venous puncture for determination:

leptin, determined by the immunoenzymatic method, Elisa Sunrise Tecan equipment, reference values 4-25 ng/ $\mathrm{mL}$;

insulin, determined by the Chemiluminiscent method, Siemens Immulite 2000 XPI equipment, reference values 2.6-24.9 $\mu \mathrm{U} / \mathrm{mL}$;

glugose, determined by the Spectrophotometric method, Abbott Architect c8000 equipment, reference values 80$120 \mathrm{mg} / \mathrm{dL}$.

HOMA-IR Blood Code Calculation $=$ Insulin $(\mu \mathrm{U} / \mathrm{mL}) \times$ Glucose (mg/dL).

The data were uploaded and processed using statistical functions in SPSS 18.0 at the significance threshold of $95 \%$.

Significance tests. Skewness or Kurtosis tests $(-2<p$ $<2$ ) are those tests measuring the normalcy of the set of values in order to establish if the variables are continuous ornot.

In calculating the significant difference between two or more groups, based on the distribution of the series of values, for the significance threshold of $95 \%$ and for the quantitative variables, we applied the t-Student test - a parametric test that compares the average values recorded in 2 groups with normal distributions.

The $\chi^{2}$ test is a nonparametric test comparing 2 or more frequencies distributed from the same population and applies when the expected events are excluded.
Sometimes, when the frequency calculation formula is small, Yates correction formula is applied to obtain a higher estimate of the difference. The Kruskall-Wallis correlation compares ordinal variables from 3 or more groups.

Pearson correlation coefficient $(r)$ represents the correlation of 2 variables in the same group, the direct / indirect correlation being given by the coefficient sign.

The Receiver Operating Characteristic (ROC) curve highlights the predictability of some laboratory markers in the determinism of immune inflammation in pregnant women.

\section{Results and discussions}

Epidemiological characteristics

Weight status

Body mass index (BMI) varied from 18.79 to $44.14 \mathrm{~kg} /$ $\mathrm{m}^{2}$, with a coefficient of variance of $29.16 \%$, the mean value of the group being $34.17 \pm 5.40 \mathrm{~kg} / \mathrm{m}^{2}$, close to the median value $\left(33.90 \mathrm{~kg} / \mathrm{m}^{2}\right)$. The results of Skewness $(p=$ $-0.403)$ and Kurtosis tests $(p=1.014)$ suggest the normal distribution of the set of BMI values recorded (fig. 1).

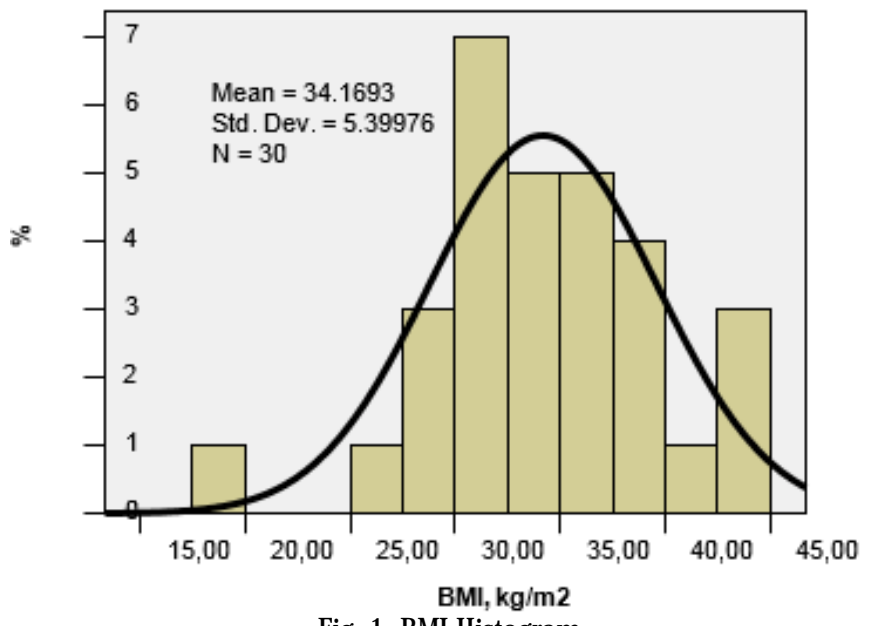

Fig. 1. BMI Histogram

The average level of the BMI set of values close to the obesity threshold $\left(34.9 \mathrm{~kg} / \mathrm{m}^{2}\right)$ provided by the specialized literature leads to the group being split in two:

Group I - 25 women with the level of BMI over $34.9 \mathrm{~kg} /$ $\mathrm{m}^{2}$, the mean value of the lot being $35.73 \pm 4.12 \mathrm{~kg} / \mathrm{m}^{2}$

Group II - 5 women with the level of BMI below $34.9 \mathrm{~kg} /$ $\mathrm{m}^{2}$, the mean value of the lot being $26.39 \pm 4.35 \mathrm{~kg} / \mathrm{m}^{2}$

Distribution by age group revealed that $56 \%$ of the total obese patients (group I) were in the 30-39 age group, while $60 \%$ of the total group II was in the $20-29$ age group (Chisquare=1.48; $d f=2 ; p=0.477)$.

\section{Maternal pathology}

Based on the cases studied, the maternal pathology associated with obesity did notinduce an estimated higher risk (table 1), but the issue could be reconsidered on a larger number of patients enrolled in a future study.

Gestational hypertension (HTA)- pregnancy-induced hypertension - was noted in $20 \%$ of obese patients and $20 \%$ of non-obese patients $(p=1.000)$.

The scarring uterus was more commonly encountered in obese patients ( $48 \%$ vs. $40 \%, p=0.743$ ), but the percentage distribution did not show statistically significant differences.

Diabetes and placenta previa were noted in only 2 obese patients. The reduced number of cases does not allow extrapolation of the results to the general population.

Stopped birth mechanism was more frequently associated with non-obese patients ( $16 \%$ vs $40 \%$; $p=0.252$ ). 
Table 1

THE RISK OF OBESITY CORRELATED WITH MATERNAL PATHOLOGY

\begin{tabular}{|l|l|l|l|l|l|l|l|l|l|}
\hline \multirow{2}{*}{ Matemal pathology } & \multicolumn{2}{|l|}{$\begin{array}{l}\text { Group I } \\
(\mathrm{n}=25)\end{array}$} & \multicolumn{2}{l|}{$\begin{array}{l}\text { Group II } \\
(\mathrm{n}=5)\end{array}$} & Chi2 & p & OR & RR & IC95\% \\
\cline { 2 - 10 } & $\mathrm{n}$ & $\%$ & $\mathrm{n}$ & $\%$ & & & & & \\
\hline Gestational HTA & 5 & 20.0 & 1 & 20.0 & 0.000 & 1.000 & 1.00 & 1.00 & $0.67-1.49$ \\
\hline Diabetes & 2 & 8.0 & 0 & 0.0 & 0.757 & 0.384 & - & 1.22 & $1.02-1.45$ \\
\hline Scarred uterus & 12 & 48.0 & 2 & 40.0 & 0.108 & 0.743 & 1.39 & 1.06 & $0.77-1.45$ \\
\hline Placenta previa & 2 & 8.0 & 0 & 0.0 & 0.757 & 0.384 & - & 1.22 & $1.02-1.45$ \\
\hline Stopped birth mechanism & 4 & 16.0 & 2 & 40.0 & 1.311 & 0.252 & 0.27 & 0.76 & $0.42-1.37$ \\
\hline
\end{tabular}

In conclusion, presence of gestational hypertension, scarring uterus, diabetes and placenta previa the maternal pathology were not risk factors for the pregnant woman.

Factors related to foetal development (table 2)

Gestational (pregnancy) age varied from 34 to 41 weeks, with a variation coefficient of $4.1 \%$, the mean value of the group being $37.47 \pm 1.55$ weeks, with a slightly reduced mean for the obese patients ( 37.44 vs 37.60 weeks; $p=0.837$ ).

The weight of the foetus ranged from 2700 to $4290 \mathrm{~g}$, with a variation coefficient of $11.7 \%$, the mean value of the group being $3440 \pm 403 \mathrm{~g}$, with a slightly increased mean for the obese patients (3461 vs $3336 \mathrm{~g} ; \mathrm{p}=0.537$ ).

The Apgar Score varied from 6 to 9 , with a variation coefficient of $10.1 \%$, the mean value of the group being $8.53 \pm 0.83$, without significant differences depending on the mother's weight status ( 8.44 vs $9.0 ; p=0.189$ ).

\section{Lab markers}

C-reactive protein (CRP)

From the obese patients only $12 \%$ showed a level of $C R P<6$. The Chi2 test revealed that the estimated risk (RR) of immune inflammation in obese patients with $C R P>6$ was over 5 times bigger ( $R R=5.1$; IC95\%: 1.38-17.39; $\mathrm{p}=0.026)$ (fig. 2).

Leptin varied from 0.62 to $61.84 \mathrm{ng} / \mathrm{mL}$, with an ample variance coefficient $(101.81 \%)$, the mean value of the group being of $15.45 \pm 15.73 \mathrm{ng} / \mathrm{mL}$, much bigger than the median value $(9.24 \mathrm{ng} / \mathrm{mL})$, which suggests the fact that

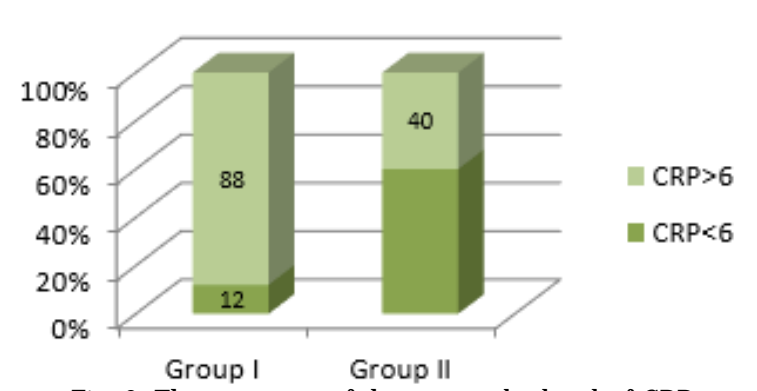

Fig. 2. The structure of the groups by level of CRP

the set of values did not have a normal distribution, aspect also confirmed by the results of the Kurtosis test $(p=2.167$ ) (table 3).

Insulin varied from 0.51 to $25.42 \mu \mathrm{U} / \mathrm{mL}$, with an ample coefficient of variance $(108.4 \%)$, the mean value of the group being $5.11 \pm 5.54 \mu \mathrm{U} / \mathrm{mL}$, much bigger than the median value $(3.35 \mathrm{ng} / \mathrm{mL})$, which suggests the fact that the set of values did not have a normal distribution, this aspectbeing also confirmed bythe results of the Skewness tests $(p=2.562)$ and Kurtosis tests $(p=6.700)$ (table 3$)$.

Blood glucose varied from 66 to $116 \mathrm{mg} / \mathrm{dL}$, with a coefficient of variance of $14 \%$, the mean value of the group being of $85.01 \pm 11.90 \mathrm{mg} / \mathrm{dL}$, close to the median value $(83.40 \mathrm{mg} / \mathrm{dL})$, which suggests the fact that the set of values had a normal distribution, this aspect being also confirmed by the results of the Skewness tests $(p=0.749)$ and Kurtosis tests $(p=0.165)$ (table 3$)$.

Homeostatic Model Assessment for Insulin Resistance (HOMA) varied from 0s11 to 6.57 , with a coefficient of

\begin{tabular}{|l|l|l|l|}
\hline Characteristics & Group I & Group II & t-Student test (p) \\
\hline BMI, $\mathrm{kg} / \mathrm{m}^{2}$ & $35.73 \pm 4.12$ & $26.39 \pm 4.35$ & 0.001 \\
\hline Age, y & $31.04 \pm 7.09$ & $29.60 \pm 6.69$ & 0.679 \\
\hline Gestational age, weeks & $37.44 \pm 1.64$ & $37.60 \pm 1.14$ & 0.837 \\
\hline Weight of the foetus, g & $3461 \pm 407$ & $3336 \pm 413$ & 0.537 \\
\hline Apgar score & $8.44 \pm 0.92$ & $9.00 \pm 0.01$ & 0.189 \\
\hline
\end{tabular}

\begin{tabular}{|l|l|l|l|l|}
\hline Statistical indicators & Leptin (ng/mL) & $\begin{array}{l}\text { Insulin } \\
(\mu \mathrm{U} / \mathrm{mL})\end{array}$ & $\begin{array}{l}\text { Glucose } \\
(\mathrm{mg} / \mathrm{dL})\end{array}$ & HOMA \\
\hline $\mathrm{N}$ & 30 & 30 & 30 & 30 \\
\hline Mean & 15.45 & 5.11 & 85.01 & 1.12 \\
\hline Median & 9.24 & 3.35 & 83.40 & 0.72 \\
\hline Std. deviation & 15.73 & 5.54 & 11.90 & 1.37 \\
\hline Variance & 101.81 & 30.67 & 141.61 & 1.88 \\
\hline Skewness & 1.569 & 2.562 & 0.749 & 2.905 \\
\hline Std. Error of Skewness & 0.427 & 0.427 & 0.427 & 0.427 \\
\hline Kurtosis & 2.167 & 6.700 & 0.165 & 8.932 \\
\hline Std. Error of Kurtosis & 0.833 & 0.833 & 0.833 & 0.833 \\
\hline Range & 61.24 & 24.91 & 50 & 6.46 \\
\hline Minimum & 0.61 & 0.51 & 66 & 0.11 \\
\hline Maximum & 61.84 & 25.42 & 116 & 6.57 \\
\hline Percentiles 25 & 3.32 & 2.13 & 75.55 & 0.40 \\
& 9.24 & 3.35 & 83.40 & 0.72 \\
\hline & 22.53 & 4.96 & 91.28 & 1.00 \\
\hline
\end{tabular}

Table 2

COMPARATIVE EPIDEMIOLOGICAL CHARACTERISTICS OF STUDIED GROUPS

Table 3

STATISTICAL INDICATORS OF THE LAB MARKERS 
variance of $122.3 \%$, the mean value of the group being of $1.12 \pm 1.37$, different from the median value (0.72), which suggests the fact that the set of values did not have a normal distribution, this aspectbeing also confirmed by the results of the Skewness $(p=2.905)$ and Kurtosis tests $(p=8.932)$ (tab.3).

The individual level of leptin correlated directly with BMI, showing the fact that in $21.8 \%$ of pregnancies the higher values of leptin were met when we recorded increased values of the $B M I\left(r=+0.218 ; R^{2}=0.0473 ; p=0.248\right)$, but the result cannot be extrapolated to the general population. The level of insulin and the BMI were apparently independent parameters $\left(r=+0.042 ; R^{2}=0.0018 ; p=\right.$ 0.825 ). The individual level of glycaemia correlated directly with the BMI, which was reduced as intensity, showing the fact that in $10,6 \%$ of the pregnancies the increased values of glycaemia were associated with increased values of the BMI ( $\left.r=+0.106 ; R^{2}=0.0107 ; p=0.576\right)$ (fig. 3).

HOMA Index and BMI were apparently independent parameters $\left(r=+0.091 ; R^{2}=0.0083 ; p=0.632\right)$.
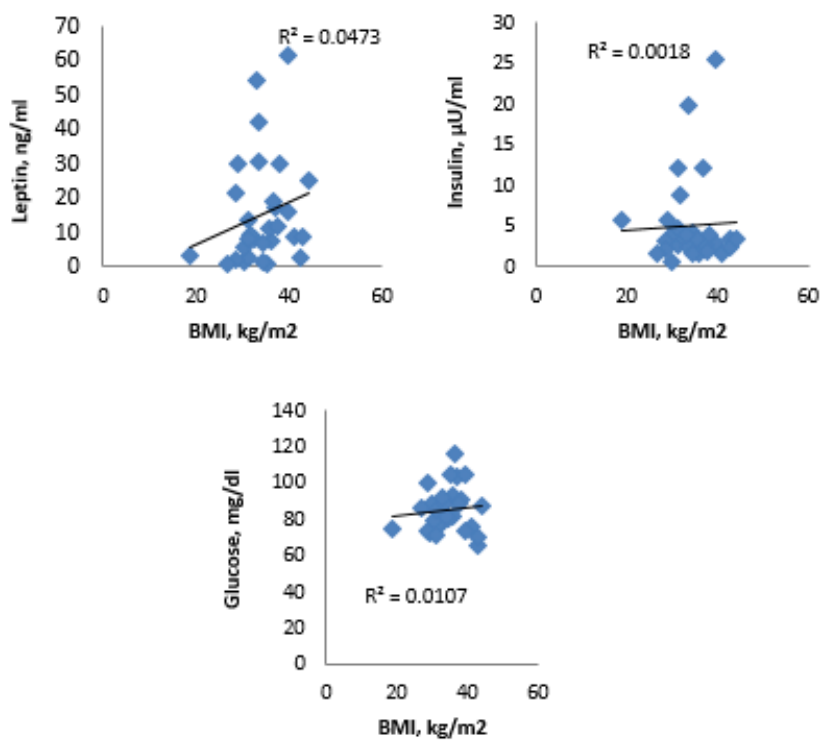

Fig. 3. The correlation of leptin, insulin and glycaemia with BMI

Assessing eating habits. The Disabilities of the Arm, Shoulder and Hand (DASH) Score

DASH score varied from 14 to 27 , with a variation coefficient of $15.1 \%$, the mean value of the group being $22.07 \pm 3.33$, which is close to the median value (22.50), suggesting the fact that the set of values had a normal distribution. This aspect is also confirmed by the results of the Skewness $(p=-0.584)$ Kurtosis tests $(p=-0.114)$ (fig 4).

DASH score correlated indirectly with the BMI, showing the fact that $30.6 \%$ of the pregnant women associate more reduced values of the DASH score with increased values of the BMI ( $\left.r=-0.306 ; R^{2}=0.0934 ; p=0.05\right)$, (fig. 5).

For the group of obese patients, the mean level of DASH score was significantly reduced ( 21.68 vs $24.0 ; p=0.05$ ) (table 4).

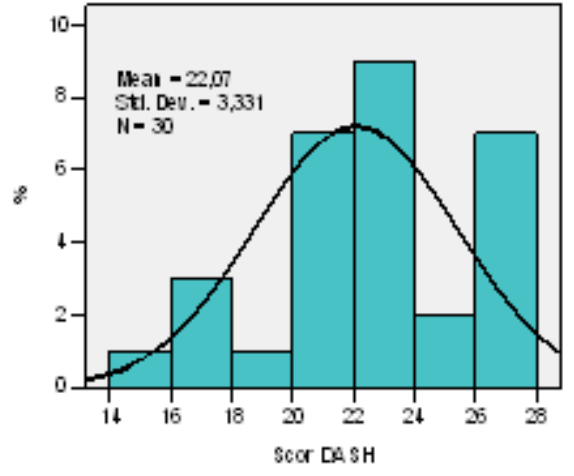

Fig 4. Histogram of DASH score

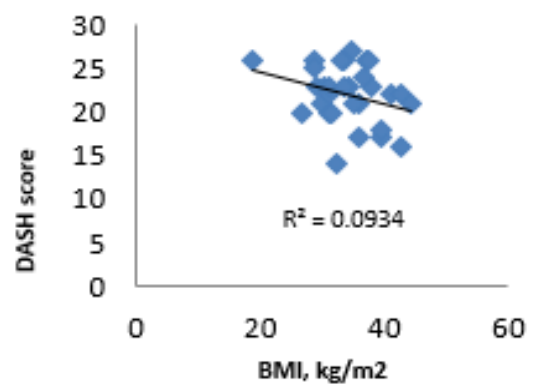

Fig 5. The correlation of DASH score with BMI

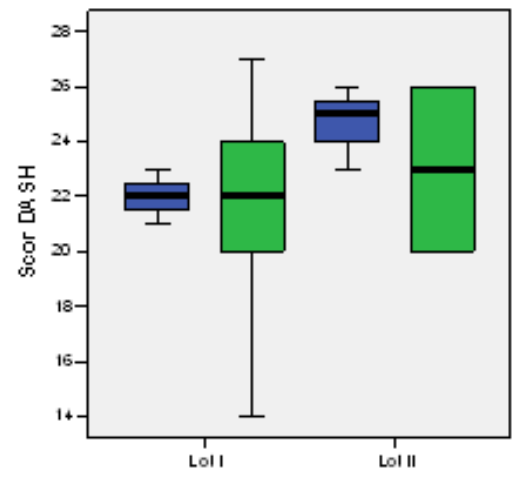

Fig. 6. Correlation of the mean DASH score with the CRP level compared to study lots

The mean DASH score was not significantly different depending on the CRP level ( $p>0.05$ ) (fig. 6).

The DASH score correlated directly, but reduced in intensity, with the level of leptin $\left(r=+0.165 ; R^{2}=0.0272\right.$; $p=0.384$ ), but the result cannot be extrapolated to the general population. The insulin level and the DASH score were apparently independent parameters $(r=-0.082$; $\left.R^{2}=0.0067 ; p=0.666\right)$. The individual level of glycaemia correlated directly with the DASH score, which was reduced as intensity, showing the fact that $22.3 \%$ of the pregnant women had increased values of glycaemia associated with increased values of the DASH score $(r=+0.223$; $R^{2}=0.0501 ; p=0.235$ ) (fig. 7).

Table 4

DESCRIPTIVE INDICATORS OF DASH SCORE COMPARED ON GROUPS STUDIED

\begin{tabular}{|c|c|c|c|c|c|c|c|c|c|}
\hline \multirow{2}{*}{ Group } & \multirow{2}{*}{$\mathrm{N}$} & \multirow{2}{*}{ Mean } & \multirow{2}{*}{$\begin{array}{l}\text { Std. } \\
\text { Deviation }\end{array}$} & \multirow{2}{*}{$\begin{array}{l}\text { Std. } \\
\text { Error }\end{array}$} & \multicolumn{2}{|c|}{ Confidence interval $95 \%$} & \multirow{2}{*}{ Min } & \multirow{2}{*}{$\operatorname{Max}$} & \multirow{2}{*}{$\begin{array}{l}\mathrm{p}-\text { Test t- } \\
\text { Student }\end{array}$} \\
\hline & & & & & $-95 \% \mathrm{CI}$ & $+95 \% \mathrm{CI}$ & & & \\
\hline Group I & 25 & 21.68 & 3.375 & 0.675 & 20.29 & 23.07 & 14 & 27 & \multirow{3}{*}{0.050} \\
\hline Group II & 5 & 24.00 & 2.550 & 1.140 & 20.83 & 27.17 & 20 & 26 & \\
\hline Total & 30 & 22.07 & 3.331 & 0.608 & 20.82 & 23.31 & 14 & 27 & \\
\hline
\end{tabular}



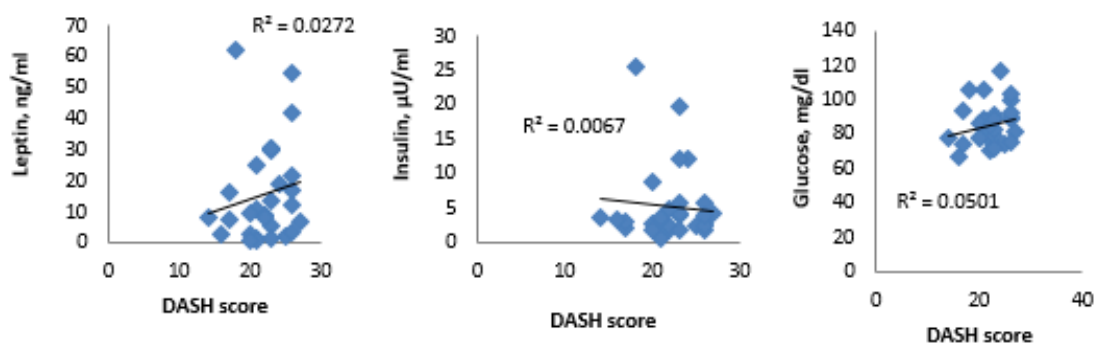

Fig. 7. Correlation of the mean DASH score with the CRP level compared to study lots

Table 5

THE ROC CURVE COORDINATES FOR OBESE PREGNANT WOMEN

\begin{tabular}{|l|l|l|l|l|l|}
\hline \multirow{2}{*}{$\begin{array}{l}\text { Test Result } \\
\text { Variable(s) }\end{array}$} & \multirow{2}{*}{$\begin{array}{l}\text { Area under curve } \\
\text { (AUC) }\end{array}$} & \multirow{2}{*}{ Std. Error(a) } & Asymptotic Sig.(b) & \multicolumn{2}{|l|}{ Asymptotic 95\% Confidence Interval } \\
\cline { 5 - 6 } & & & & Lower Bound & Upper Bound \\
\hline CRP & 0.740 & 0.140 & 0.095 & 0.466 & 1.014 \\
\hline Leptin, $\mathrm{ng} / \mathrm{ml}$ & 0.616 & 0.163 & 0.420 & 0.296 & 0.936 \\
\hline Insulin, $\mu \mathrm{U} / \mathrm{ml}$ & 0.536 & 0.149 & 0.802 & 0.244 & 0.828 \\
\hline Glycaemia, $\mathrm{mg} / \mathrm{dl}$ & 0.648 & 0.142 & 0.303 & 0.369 & 0.927 \\
\hline HOMA & 0.496 & 0.142 & 0.978 & 0.217 & 0.775 \\
\hline
\end{tabular}

HOMA level and DASH score were apparently independent parameters $\left(r=-0.079 ; R^{2}=0.0063 ; p=\right.$ 0.676).

By drawing the ROC curve on the cases studied, we noticed the fact that of the markers determined from the blood samples only CRP (AUC $=0.740$; IC95\%: 0.4661.014), leptin ( $A \cup C=0.616$; IC95\%: 0.296-0.936) and glycaemia (AUC=0.648; IC95\%: 0.369-0.927) were good indicators of immune inflammation (table 6, fig. 8).

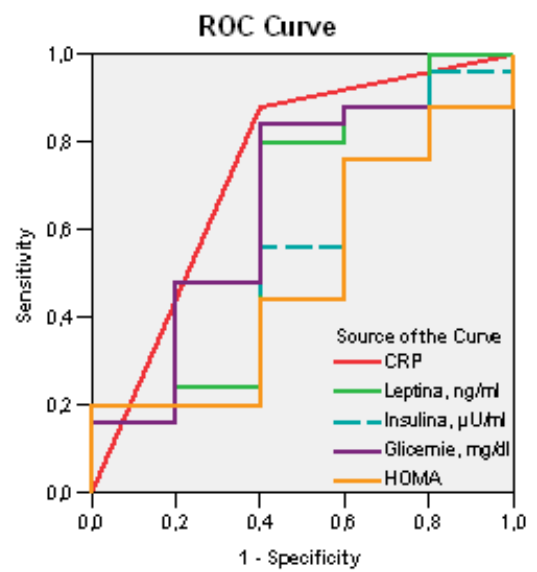

Fig. 8. The balance sensitivity / specificity of Laboratory Parameters in identifying the immune inflammation in obese pregnant women

-CRP: cut off value 6 , sensitivity $88 \%$, specificity $62 \%$ -Leptin: cut off value $6.27 \mathrm{ng} / \mathrm{mL}$, sensitivity $79 \%$, specificity $60 \%$

-glucose: cut off value $80 \mathrm{mg} / \mathrm{gL}$, sensitivity $82 \%$, specificity $60 \%$.

The test result variable(s): CRP has at least one tie between the positive actual state group and the negative actual state group. Statistics may be biased.

a Under the nonparametric assumption

b Null hypothesis: true area $=0.5$

Beyond the mechanisms, how ever, it is clear that the risks of abdominal obesity (quantified by abdominal circumference and waist / hip ratio) are significant. Abdominal obesity is an important factor associated with immune inflammation and various metabolic disorders, independent of other factors, including body mass index $[2,12]$.

During pregnancy in obese women we have identified significant changes in leptins and more modest changes in insulin or glucose with some evidence that this is more pronounced than in pregnant women with a normal weight [13].

Autophagy in adipose tissue of obese people correlates with obesity, visceral fat distribution and adipocyte hypertrophy. This may coincide with insulin resistance but precedes the occurrence of obesity related morbidity [11].

\section{Conclusions}

The group that was studied was made of 30 pregnant women with immune inflammation, with a mean age of $30.80 \pm 6.94$ years old

The maternal pathology of the obese pregnant group was dominated by the scarred uterus (48\%) and pregnancy induced blood hypertension (20\%). We have also identified some cases where the birth mechanism stopped (16\%), placenta previa (8\%) and associated diabetes (8\%).

In the group of obese pregnant women, factors related to the development of the foetus revealed an average gestational age of $37.44 \pm 1.64$ weeks, a mean weight of the foetus of $3461 \pm 407 \mathrm{~g}$ and the mean Apgar score of $8.44 \pm 0.92 .00$

The estimated risk of immune inflammation is 5 times higher in obese pregnant women with a CRP value over 6.

The DASH score varied from 14 to 27 , with a mean value of $2.07 \pm 3.33$, significantly reduced in obese patients (21.68 vs $24 ; p=0.05$ ).

About $30 \%$ of the pregnant women associated higher values of BMI with higher values of leptin and glycemia.

The change in the lifestyle can contribute to a healthier metabolic profile for the obese pregnant women, but the results require further studies.

\section{References}

1.***Waist Circumference and Waist-Hip Ratio: Report of a WHO Expert Consultation Geneva, 8-11 December 2008, available at http:/ /whqlibdoc.who.int/publications/2011/9789241501491_eng.pdf, accessed 1.02.2018.

2.HARDY O.T., PERUGINI R.A., NICOLORO S.M., et al. (2011). Body mass index-independent inflammation in omental adipose tissue associated with insulin resistance in morbid obesity. Surg Obes Relat Dis; 7: 60-67. 
3.LIJ NEN H.R. (2008). Angiogenesis and obesity, Cardiovasc Res. 78(2): 286-293.

4.LUPU, V. V., IGNAT, A., STOLERIU, G., CIUBARA, A. B., CIUBARA, A., LUPU, V., BURLEA, M., STRATCIUC, S., Vaccination of Children in Romania between Civic Obligation and Personal Choice, Revista de Cercetare si Interventie Sociala, 2017, vol. 56: 123-132

5.STRATICIUC, S., IGNAT, A., HANGANU, E., LUPU, V. V., CIUBARA, A.B., CRETU, R., Neisseria meningitidis Serogroup C Causing Primary Arthritis in a Child Case Report, Medicine, 2016, vol. 95(5), Article Number: e2745

6.CRAUCIUC, D. V., CRAUCIUC, E. G., IOV, C. J ., FURNICA, C., IOV, T., Non-invasive Evaluation of Neonatal Cerebral Status in the Newborns of Mothers Addicted to Alcohol and Drugs, Rev.Chim.(Bucharest),69, no.11, 2018, p.4088-4092

7.SAHAKYAN, K.R., et al. (2015). Normal-Weight Central Obesity: Implications for Total and Cardiovascular Mortality Ann Intern Med. 2015; 163(11): 827-835.

8.IMANI, B., EIJKEMANS, M.J ., TEVELDE, E.R., et al. (2002). A nomogram to predict the probability of live birth after clomiphene citrate induction în normogonadotrophic oligoamenorrheie infertility. Fertil Steril. 77(1): 91-7.

9.VANDANMAGSAR, B., YOUM, Y.H., RAVUSSIN, A., et al. (2011). The NLRP3 inflammasome instigates obesity-induced inflammation and insulin resistance. Nat Med; 17: 179-188.

10.KOVSAN J., BLUHER. M., TARNOVSCKI. T., et al. (2011). Altered autophagy in human adipose tissues in obesity. J Clin Endocrinol Metab; 96: E268-E277.

11.MAIXNER N., KOVSAN. J., HARMAN-BOEHM I., et al. (2012). Autophagy in adipose tissue. Obes Facts, 5(5): 710-721.

12.NADEEM B., BACHA R., GILANI S.A (2018). Correlation of Subcutaneous Fat Measured on Ultrasound with Body Mass Index. J Med Ultrasound; 26(4): 205-209.

13.MILLS, H.L., PATEL, N., WHITE, S.L., et al. (2019). The effect of a lifestyle intervention in obese pregnant women on gestational metabolic profiles: findings from the UK Pregnancies Better Eating and Activity Trial (UPBEAT) randomised controlled trial. BMC Med.; 17(1):15.

Manuscript received: 6.10 .2018 